Mr Boban Bondžulić, kapetan, dipl. inž.

Vojna akademija,

dr Vladimir Petrović,

Imaging Science,

University of Manchester

\section{OBJEKTIVNE MERE PROCENE REZULTATA SJEDINJAVANJA SLIKA}

UDC: 621.397 .331

Rezime:

U radu je opisano nekoliko objektivnih mera za procenu rezultata multisenzorskog sjedinjavanja slika, koje se koriste ukoliko postoji idealna sjedinjena slika i mere koje se koriste kada se ona ručno ili automatski ne može dobiti. Analizom sjedinjenih slika, dobijenih na pet različitih načina, izvršeno je poređenje opisanih mera.

Ključne reči: multisenzorsko sjedinjavanje slika, subjektivne i objektivne mere procene rezultata sjedinjavanja, ivice slike, zajednička informacija, univerzalni indeks kvaliteta slike.

\title{
OBJECTIVE IMAGE FUSION PERFORMANCE MEASURES
}

Summary:

In this paper some objective image fusion performance measures are described. The measures which can be used if ground truth or the ideal fused image is known are described as well as the measures which can be used if the ideal fused image cannot be obtained manually or via a reliable procedure. The objective image fusion performance measures are compared by analyzing the results of five different image fusion methods.

Key words: multisensor image fusion, subjective and objective image fusion performance measures, image edges, mutual information, universal image quality index.

\section{Uvod}

Jedna metoda neće biti dobra za sve primene. Takođe, različite metode sjedinjavanja slika nisu podjednako korisne za konkretnu primenu, pa je procena rezultata sjedinjavanja značajna, kako za izbor odgovarajuće metode, tako i za optimalan izbor parametara koji su potrebni za pojedine metode sjedinjavanja.

Uobičajena praksa za procenu rezultata sjedinjavanja zasnovana je na proceni rezultata koju obavlja određeni broj posmatrača (subjektivna procena). Da bi se dobili statistički relevantni rezultati potreban je znatan broj posmatrača (reprezentativan uzorak) i kontrolisani uslovi sprovođenja eksperimenta. Pored toga, potrebno je sprovesti dodatnu obradu odgovora posmatrača, što subjektivnu procenu čini vremenski dugom i veoma skupom (sl. 1).

Da bi se izbegla subjektivna procena, potrebna je procedura za automatsku procenu rezultata sjedinjavanja, koja se naziva objektivna procena. Pri ovoj proceni obavlja se sjedinjavanje test-slika koje su relevantne za konkretnu primenu. Algoritam koji daje najbolje rezultate zatim se koristi u konkretnoj aplikaciji. 


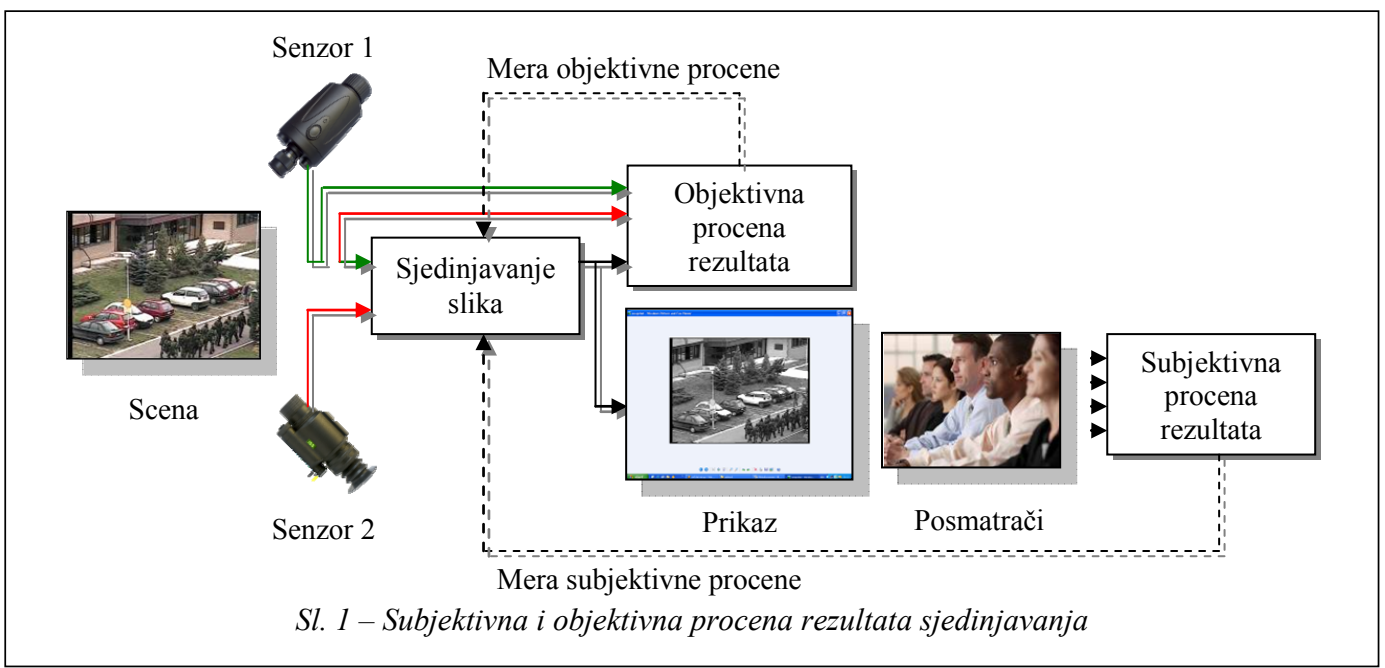

Ovakve metode često se nazivaju i metode neslaganja, jer se rezultati sjedinjavanja porede sa referentnim sjedinjavanjem. Referentno ili idealno sjedinjavanje može se dobiti ručno ili pomoću pouzdane procedure. Procena se dobija poređenjem rezultata ispitivane metode i rezultata idealnog sjedinjavanja.

Objektivne mere procene imaju značajnu ulogu u različitim primenama obrade slike. Najčešće se koriste $u$ kompresiji slike, kada je potrebno kvantitativno proceniti razliku između komprimovane i referentne slike. Njihova primena je moguća kada postoji referentna slika za poređenje sa rezultatom obrade.

Za procenu odstupanja najčešće se koristi srednja kvadratna greška (mean squared error - MSE), koja se definiše kao:

$$
\sigma_{m s}^{2}=\frac{1}{M N} \sum_{m=1}^{M} \sum_{n=1}^{N}(A(m, n)-F(m, n))^{2}
$$

gde je sa A označena referentna slika, a sa $\mathrm{F}$ slika koja je rezultat obrade referentne slike. Obe slike su dimenzija $\mathrm{M} \times \mathrm{N}$ piksela.
Najčešće se srednja kvadratna greška izražava pomoću odnosa signal/šum (u dB) kao:

$\mathrm{SNR}=10 \log \frac{\sigma^{2}}{\sigma_{m s}^{2}}$

gde je $\sigma^{2}$ varijansa referentne slike.

Opisane mere ne daju uvek pravu meru kvaliteta slike, jer ne uzimaju u obzir osobine vizuelnog sistema čoveka [1]. Međutim, one se i dalje koriste, jer su jednostavne za izračunavanje i nisu računarski zahtevne. Takođe, nezavisne su od uslova pod kojima se procena sprovodi.

Pri proceni rezultata sjedinjavanja izvornih slika, osim u veoma specifičnim aplikacijama kao što je sjedinjavanje slika sa različitim fokusima, idealna sjedinjena slika se ručno ili automatski ne može dobiti. Zbog toga će biti opisane objektivne mere procene rezultata sjedinjavanja, a koje ne koriste idealnu sjedinjenu sliku. Opisane mere mogu se razvrstati u tri grupe. To su: ivična objektivna procena, objektivna procena zasnovana na zajedničkim informacijama i objektivna procena zasnovana na univerzalnom indeksu kvaliteta slike. 


\section{Ivična objektivna procena rezultata sjedinjavanja}

Teoretski cilj sjedinjavanja slika jeste predstavljanje informacija izvornih slika u jednoj kompozitnoj slici, bez distorzije ili gubitka informacija. Kako je u praksi predstavljanje svih informacija izvornih slika preko sjedinjene slike retko moguće, praktični cilj sjedinjavanja je verna reprezentacija najbitnijih informacija izvornih slika u sjedinjenoj slici [2].

Objektivna procena rezultata sjedinjavanja, predložena u [2], povezuje informacije sa ivicama. Prvo se vrši izdvajanje parametara izvornih ivica i sjedinjene slike. Zatim se određuju mere održanja ivica, koje prikazuju koliko su verno preslikane izvorne ivice u sjedinjenoj slici. Određivanjem subjektivnog značaja piksela izvornih slika dobijaju se numeričke vrednosti kojima se modulišu mere održanja ivica i rezultat integrali po svim pikselima. Kao rezultat dobija se numerička vrednost koja pokazuje uspešnost sjedinjavanja.

Izdvajanje parametara ivica može se ostvariti pomoću Sobel operatora, pri čemu se dobijaju x i y komponente ivica $\left(\mathrm{S}^{\mathrm{x}}\right.$ i $\left.\mathrm{S}^{\mathrm{y}}\right)$ izvornih slika A i B i sjedinjene slike F. Parametri ivica su amplitude (moduo gradijenta) g i orijentacije, a dobijaju se od komponenti $\mathrm{S}^{\mathrm{x}}$ i $\mathrm{S}^{\mathrm{y}}$ kao:

$$
\begin{aligned}
g_{I} & =\sqrt{S_{I}^{x^{2}}+S_{I}^{y^{2}}} \\
\mathrm{i} \alpha_{I} & =\arctan \left(S_{I}^{y} S_{I}^{x^{-1}}\right), I \quad A, B, F
\end{aligned}
$$

Ivica izvorne slike je sasvim preslikana u sjedinjenu sliku ako su amplitude i orijentacije ostale nepromenjene. Prome- na jednog ili oba parametra jeste pokazatelj gubitka informacija. Ukoliko postoji gubitak informacija od izvorne slike A do sjedinjene slike $\mathrm{F}$, promena amplitude, ${ }_{\mathrm{g}}^{\mathrm{AF}}$, definiše se sledećom relacijom:

$\Delta_{g}^{A F}(m, n)= \begin{cases}\frac{g_{F}(m, n)}{g_{A}(m, n)}, & g_{A}(m, n)>g_{F}(m, n) \\ \frac{g_{A}(m, n)}{g_{F}(m, n)}, & g_{F}(m, n) \geq g_{A}(m, n)\end{cases}$

Promena orijentacije ivica slike $\mathrm{F} u$ odnosu na sliku A, ${ }^{\mathrm{AF}}$ definiše se kao normalizovana razlika orijentacija ${ }_{A} \mathrm{i} \quad \mathrm{F}$ :

$\Delta_{\alpha}^{A F}=\frac{|| \alpha_{A}(m, n)-\alpha_{F}(m, n)|-\pi / 2|}{\pi / 2}$

Da bi se modelovao gubitak informacija uzeta je u obzir i nelinearna priroda vizuelnog sistema čoveka. Gubitak amplituda i orijentacija ivica modulisan je nelinearnim sigmoidnim funkcijama, tako da se dobijaju mere održanja amplituda i orijentacija, $\mathrm{Qg}_{\mathrm{g}}^{\mathrm{AF}}$ i $\mathrm{Q}^{\mathrm{AF}}$ :

$$
Q_{i}^{A F}(m, n)=\frac{\Gamma_{i}}{1+\exp \left\{k_{i}\left[\Delta_{t}^{A F}(m, n)-\sigma_{i}\right]\right\}}
$$

$i \quad g$

U radu su korišćene vrednosti parametara $\left[\mathrm{k}_{\mathrm{g}}, \mathrm{g}, \mathrm{k}, \quad\right]=[-11,0.7,-24,0.8]$, preuzete iz literature [2]. Konstante i dobijaju se tako da je $\mathrm{Q}_{\mathrm{i}}^{\mathrm{AF}}=1$ kada je ${ }_{i}^{\mathrm{AF}}=1$.

Mere održanja amplituda i orijentacija $\mathrm{Q}_{\mathrm{g}}{ }^{\mathrm{AF}}$ i $\mathrm{Q}^{\mathrm{AF}}$ kombinuju se u meru održanja ivica $\mathrm{Q}^{\mathrm{AF}}$, koja predstavlja meru vernosti kojom slika F predstavlja sliku A: 


$$
Q^{A F}(m, n)=\left[Q_{g}^{A F}(m, n) \cdot Q_{\alpha}^{A F}(m, n)\right]^{1 / 2}
$$

Vrednosti $\mathrm{Q}^{\mathrm{AF}}$ nalaze se u opsegu $[0$ 1], gde $\mathrm{Q}^{\mathrm{AF}}=0$ ukazuje na kompletan gubitak informacija izvorne slike, dok $\mathrm{Q}^{\mathrm{AF}}=1$ ukazuje na potpuni transfer informacija.

Značaj piksela izvornih slika predstavljen je preko numeričkih koeficijenata $\mathrm{w}_{\mathrm{I}}(\mathrm{m}, \mathrm{n}), \mathrm{I}\{\mathrm{A}, \mathrm{B}\}$. Subjektivni značaj određen je na osnovu amplituda ivica, tako da je $\mathrm{w}_{\mathrm{I}}(\mathrm{m}, \mathrm{n})=\mathrm{g}_{\mathrm{I}}(\mathrm{m}, \mathrm{n})$.

Krajnja mera rezultata sjedinjavanja slika A i B, $\mathrm{Q}^{\mathrm{AB} / \mathrm{F}}$, dobija se kao normalizovana suma mera održanja ivičnih parametara piksela izvornih slika, $\mathrm{Q}^{\mathrm{AF}} \mathrm{i}^{\mathrm{BF}}$, modulisanih mapama subjektivnog značaja $\mathrm{w}_{\mathrm{A}}$ i $\mathrm{w}_{\mathrm{B}}$ :
Vrednosti mere $\mathrm{Q}^{\mathrm{AB} / \mathrm{F}}$ nalaze se $\mathrm{u}$ opsegu [0 1], gde vrednost nula ukazuje na to da je došlo do potpunog gubitka informacija izvornih slika, dok vrednost jedan ukazuje da se radi o idealnom sjedinjavanju, pri kojem su informacije izvornih slika u potpunosti preslikane u sjedinjenu sliku. Za metodu sjedinjavanja koja daje veću vrednost $Q^{A B / F}$ kaže se da je bolja za izvorne slike A i B.

Primer sjedinjavanja izvornih slika i procene rezultata sjedinjavanja prikazan je na sl. 2. Na ovoj slici su prikazane izvorne slike $\mathrm{A}$ i $\mathrm{B}$, mere održanja ivica $\mathrm{Q}^{\mathrm{AF}}$ i $\mathrm{Q}^{\mathrm{BF}}$, mape značaja $\mathrm{w}_{\mathrm{A}}$ i $\mathrm{w}_{\mathrm{B}}$ (crni pikseli 0 , beli pikseli 1) i sjedinjena slika. Izvorne slike dobijene su sa televizijske i termovizijske kamere.

$Q^{A B / F}=\frac{\sum_{m=1}^{M} \sum_{n=1}^{N}\left(Q^{A F}(m, n) w_{A}(m, n)+Q^{B F}(m, n) w_{B}(m, n)\right)}{\sum_{i=1}^{M} \sum_{j=1}^{N}\left(w_{A}(i, j)+w_{B}(i, j)\right)}$

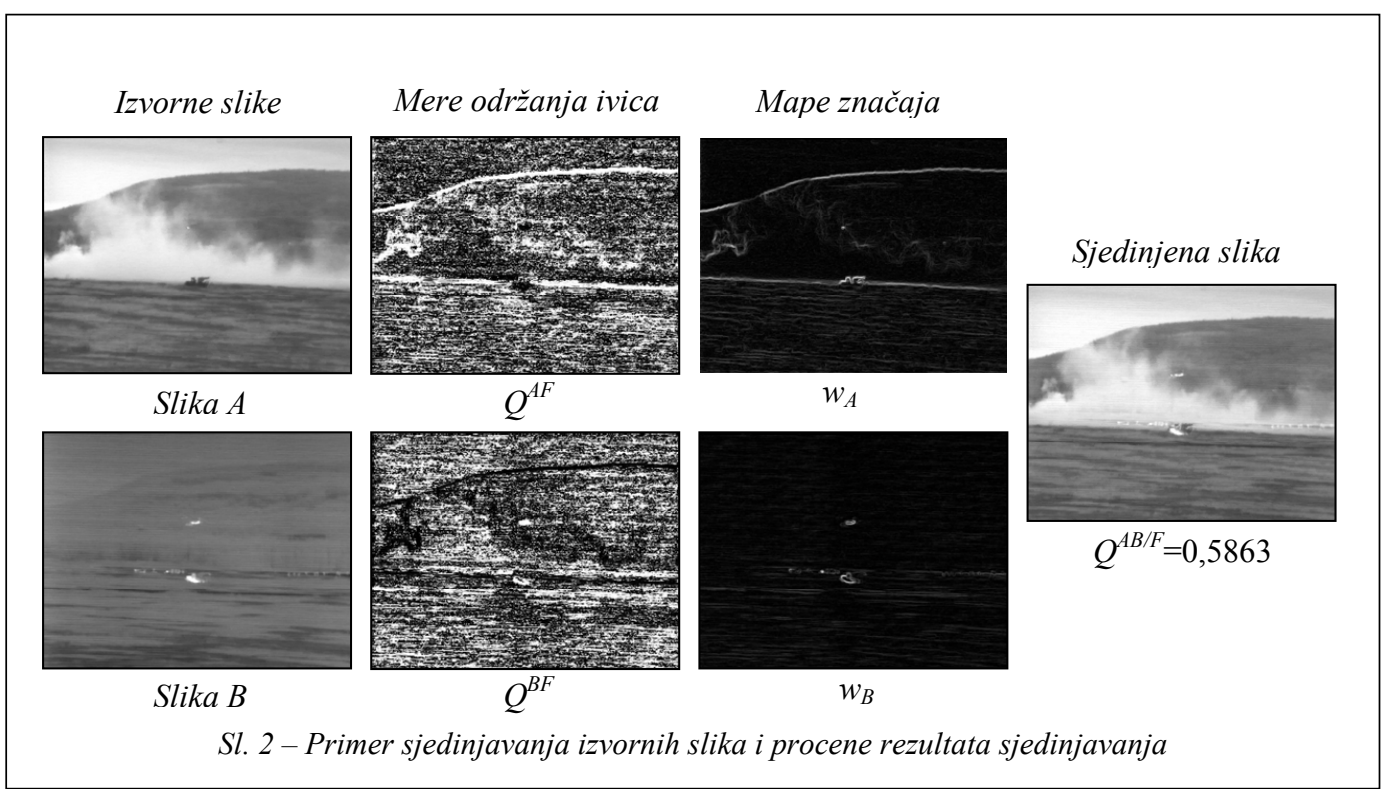


Sjedinjena slika sadrži informacije obe izvorne slike, sa bitnim obeležjima koja su preneta iz izvornih slika: bele linije i strukture na $\mathrm{Q}^{\mathrm{AF}}$ i $\mathrm{Q}^{\mathrm{BF}}$. Krajnji rezultat objektivne procene rezultata sjedinjavanja iznosi $\mathrm{Q}^{\mathrm{AB} / \mathrm{F}}=0,5863$.

\section{Zajednička informacija kao objektivna mera procene rezultata sjedinjavanja}

U [3] se za određivanje kvaliteta sjedinjavanja koristi zajednička informacija izvornih slika i sjedinjene slike.

Zajednička informacija slika $A$ i $B$ definiše se kao:

$$
I(A, B)=\sum_{a} \sum_{b} p(a, b) \cdot \log \frac{p(a, b)}{p(a) p(b)}
$$

gde su $\mathrm{p}(\mathrm{a})$ i $\mathrm{p}(\mathrm{b})$ marginalne raspodele nivoa sivog, a $\mathrm{p}(\mathrm{a}, \mathrm{b})$ združena raspodela nivoa sivog slika A i B.

Ako imamo dve izvorne slike A i B i sjedinjenu sliku $F$, količina prenesenih informacija od izvornih slika $u$ sjedinjenu sliku dobija se sledećim relacijama:

$$
\begin{aligned}
& I(A, F)=\sum_{a, f} p(a, f) \log \frac{p(a, f)}{p(a) p(f)} \mathrm{i} \\
& I(B, F)=\sum_{b, f} p(b, f) \log \frac{p(b, f)}{p(b) p(f)}(10)
\end{aligned}
$$

Performanse sjedinjavanja izvornih slika određuju se kao:

$M I_{F}^{A B}=\frac{I(A, F)+I(B, F)}{H(A)+H(B)}$

gde su H(A) i H(B) entropije nivoa sivog izvornih slika, a dinamički opseg mere MI je [ [ $\left.\begin{array}{ll}0 & 1\end{array}\right]$.

Na sl. 3 prikazane su dve izvorne slike i rezultati sjedinjavanja na dva različita načina. Izvorne slike dobijene su računarskom tomografijom i magnetskom rezonancom.

Sa sl. 3 vidi se da sjedinjena slika $F_{1}$ sadrži više informacija izvornih slika nego sjedinjena slika $F_{2}$, što se potvrdilo i analizom količine prenesenih informacija $\left(M I_{F_{1}}^{A B}>M I_{F_{2}}^{A B}\right)$.

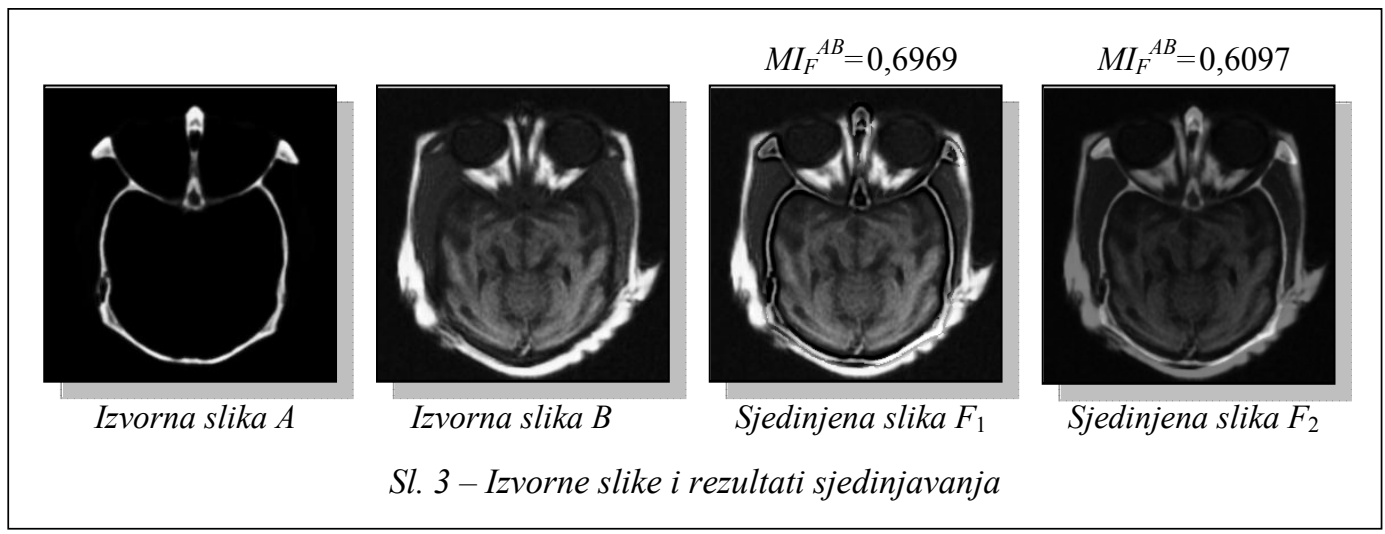




\section{Objektivne mere procene rezultata sjedinjavanja zasnovane na univerzalnom indeksu kvaliteta slike}

Neka su date slike A i B dimenzija MxN piksela. Označimo sa $\bar{A}$ i $\bar{B}$ srednje vrednosti nivoa sivog slika, sa $\mathrm{A}^{2} \mathrm{i}$ $B^{2}$ varijanse nivoa sivog slika i sa $A B$ kovarijansu slika A i B.

Mera $Q$ se definiše:

$$
Q=\frac{\sigma_{A B}}{\sigma_{A} \sigma_{B}} \cdot \frac{2 \bar{A} \bar{B}}{\bar{A}^{2}-\bar{B}^{2}} \cdot \frac{2 \sigma_{A} \sigma_{B}}{\sigma_{A}^{2}+\sigma_{B}^{2}}
$$

Wang i Bovik [4] su koeficijent Q nazvali univerzalni indeks kvaliteta slike (a universal image quality index - UIQI) i koristili ga za kvantitativno predstavljanje strukturne distorzije između slika A i B.

Dinamički opseg mere $Q$ je $\left[\begin{array}{ll}-1 & 1\end{array}\right]$. Indeks kvaliteta modeluje distorziju kao kombinaciju tri različita faktora: distorziju korelacije, distorziju osvetljenosti i distorziju kontrasta. Prvi član u izrazu je koeficijent korelacije koji pokazuje stepen linearne korelacije između slika A i B. Dinamički opseg koeficijenta korelacije je [-1 1]. Drugi član, sa dinamičkim opsegom [0 1], pokazuje koliko su blizu srednje vrednosti nivoa sivog slika A i B. Devijacije A i B mogu se posmatrati kao estimacije kontrasta slika, tako da treći član u izrazu pokazuje koliko su blizu kontrasti slika. Dinamički opseg trećeg člana je [ $\left[\begin{array}{ll}0 & 1\end{array}\right]$.

Mera kvaliteta izračunava se u lokalnim regionima slike, uz korišćenje pokretnog prozora. Polazeći od gornjeg levog dela slike, pokretni prozor $\mathrm{w}$, dimenzija LxL piksela, pomera se horizontalno i vertikalno, sve do donjeg desnog dela slike. Indeks kvaliteta određuje se u svakom prozoru. Krajnji indeks kvaliteta dobija se kao:

$$
Q(A, B)=\frac{1}{M N} \sum_{m=1}^{M} \sum_{n=1}^{N} Q(A, B / w)
$$

Piella [5] je koristio indeks kvaliteta da definiše meru Q(A, B, F) za procenu rezultata sjedinjavanja izvornih slika, gde su A i B izvorne slike, a F sjedinjena slika.

Mera koja će reprezentovati lokalni značaj prozora w na slici A označena je sa $s(A / w)$. Ova mera može zavisiti od kontrasta, varijanse ili entropije unutar prozora. Ako se poznaju mere $\mathrm{s}(\mathrm{A} / \mathrm{w}) \mathrm{i}$ s(B/w) slika A i B, može se izračunati lokalni značaj $\quad$ A $(w)$ prozora slike A u odnosu na prozor slike B. Odgovarajući izbor za $A(w)$ je [5]:

$$
\lambda_{A}(w)=\frac{s(A / w)}{s(A / w)+s(B / w)}
$$

$\mathrm{Na}$ isti način se računa ${ }_{B}(w)$. Mera kvaliteta sjedinjavanja $\mathrm{Q}_{0}(\mathrm{~A}, \mathrm{~B}, \mathrm{~F})$ data je sa:

$$
\begin{aligned}
& Q_{0}(A, B, F)=\frac{1}{|W|} \\
& \sum_{w \in W}\left(\lambda_{A}(w) Q(A, F / w)+\lambda_{B}(w) Q(B, F / w)\right)
\end{aligned}
$$

gde je W skup svih prozora, a $|\mathrm{W}|$ njihov ukupan broj.

Sada treba definisati drugu varijantu mere kvaliteta sjedinjavanja, koja će dati veći značaj prozorima izvornih slika koji imaju veći lokalni značaj. Značaj prozora definiše se kao $\mathrm{C}(\mathrm{w})=\max (\mathrm{s}(\mathrm{A} / \mathrm{w})$, 
$\mathrm{s}(\mathrm{B} / \mathrm{w}))$. Težinska mera kvaliteta sjedinjavanja definiše se kao:

$$
Q_{w}(A, B, F)=\sum_{w \in W} c(w)\left(\begin{array}{l}
\lambda_{A}(w) Q(A, F / w)+ \\
+\lambda_{B}(w) Q(B, F / w)
\end{array}\right)
$$

gde je:

$$
c(w)=C(w) /\left(\sum_{w \in W} C(w)\right)
$$

U [5] je predložena i krajnja modifikacija mere kvaliteta sjedinjavanja koja uzima u obzir ivice izvornih slika i sjedinjene slike. Koristeći modul gradijenta umesto nivoa sivog, može se izračunati mera $\mathrm{Q}_{\mathrm{w}}$. Modul gradijenta slike A ozna- čen je sa A'. Ako se vrednosti $\mathrm{Q}_{\mathrm{w}}(\mathrm{A}, \mathrm{B}$, F) i $Q_{w}\left(A^{\prime}, B^{\prime}, F^{\prime}\right)$ kombinuju u ivično zavisnu meru kvaliteta sjedinjavanja, dobija se:

$$
Q_{e}=Q_{w}(A, B, F)^{1-\alpha} \cdot Q_{w}\left(A^{\prime}, B^{\prime}, F^{\prime}\right)^{\alpha}
$$

gde parametar [0 $\left[\begin{array}{ll}0 & 1\end{array}\right]$ izražava doprinos modula gradijenta $u$ odnosu na doprinos nivoa sivog izvornih slika.

Sve tri predložene mere imaju dinamički opseg [ $\left.\begin{array}{ll}-1 & 1\end{array}\right]$. Što su mere bliže jedinici, to je više informacija izvornih slika preneto u sjedinjenu sliku.

$\mathrm{Na}$ sl. 4 prikazane su dve izvorne slike, mape značaja blokova izvornih slika i rezultati sjedinjavanja na dva različita načina.

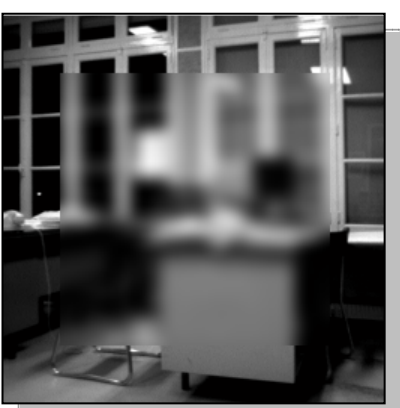

Izvorna slika $A$

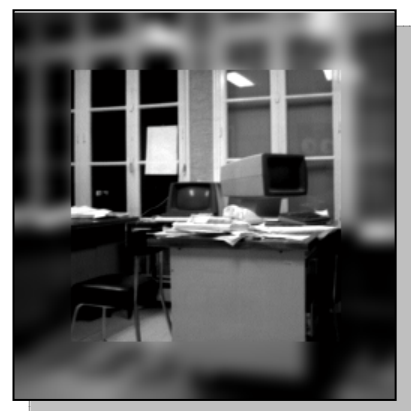

Izvorna slika B

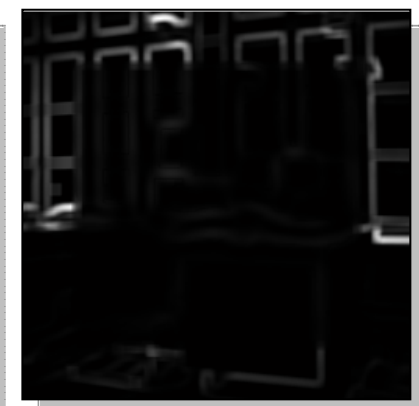

Mapa značaja c(w) ${ }_{A}(w)$

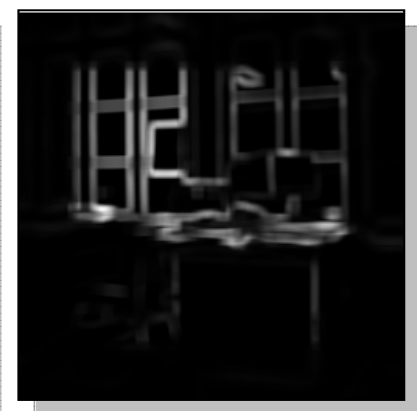

Mapa značaja c(w) ${ }_{B}(w)$

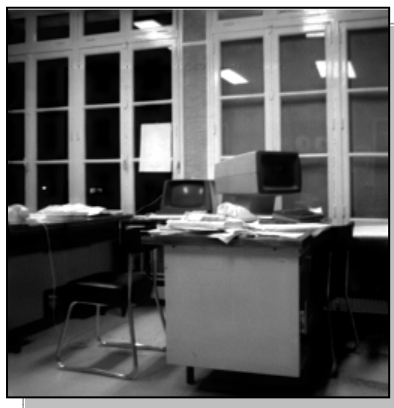

Sjedinjena slika $F_{1}$

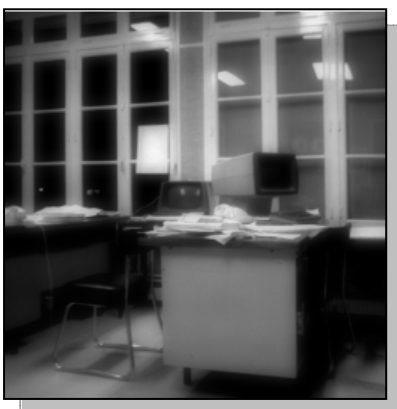

Sjedinjena slika $F_{2}$

Sl. 4 - Izvorne slike, mape značaja blokova izvornih slika i slike dobijene sjedinjavanjem 
Slika 4 pokazuje da veći značaj imaju blokovi koji se nalaze u nefiltriranim delovima izvornih slika, odnosno u delovima izvornih slika u kojima postoje izražene ivice. Po proceni posmatrača, sjedinjena slika $F_{1}$ sadrži više informacija izvornih slika od slike $\mathrm{F}_{2}$.

Za izvorne i sjedinjene slike, prikazane na sl. 4, vrednosti mera predloženih u [5] prikazane su u tabeli 1 .

\begin{tabular}{|c|c|} 
Vrednosti mera za procenu rezultata sjedinjavanja \\
izvornih slika
\end{tabular}

Iz tabele 1 vidi se da se vrednosti objektivnih mera procene rezultata sjedinjavanja $\mathrm{Q}_{w}$ i $\mathrm{Q}_{\mathrm{e}}$ slažu sa procenom posmatrača, za razliku od mere $\mathrm{Q}_{0}$.

Pri proračunu lokalnog značaja prozora $A(w)$, odnosno $B(w)$, korišćena je varijansa bloka izvorne slike (srednja vrednost za slike modula gradijenta) dimenzija $8 \times 8$ piksela, što nije mera sličnosti prozora izvorne slike sa prozorom sjedinjene slike. Dimenzija bloka ima značajan uticaj na predložene mere sjedinjavanja, jer se količnik varijansi prozora izvornih slika znatno menja sa promenom dimenzija prozora. Pored toga, kada se računa vrednost mere $Q_{e}$ potrebno je odrediti module gradijenata izvornih sli$\mathrm{ka}$, modul gradijenta sjedinjene slike $\mathrm{i}$ vrednost $Q_{w}\left(A^{\prime}, B^{\prime}, F^{\prime}\right)$, što utiče na računarsku zahtevnost mere. Zbog toga je u [6] predložena mera zasnovana na univerzalnom indeksu kvaliteta slike, a koja uzima u obzir sličnost blokova izvornih slika i sjedinjene slike. Ova mera definiše se kao:

$$
\begin{aligned}
& Q_{b}(A, B, F)= \\
& =\sum_{w \in W}\left(\begin{array}{l}
\operatorname{sim}(A, B, F / w) \cdot Q(A, F / w)+ \\
+(1-\operatorname{sim}(A, B, F / w)) \cdot Q(B, F / w)
\end{array}\right)
\end{aligned}
$$

gde je:

$$
\operatorname{sim}(A, B, F / w)=\left\{\begin{array}{cc}
0, & \frac{\sigma_{A F}}{\sigma_{A F}+\sigma_{B F}}<0 \\
\frac{\sigma_{A F}}{\sigma_{A F}+\sigma_{B F}}, & 0 \leq \frac{\sigma_{A F}}{\sigma_{A F}+\sigma_{B F}} \leq 1 \\
1, & \frac{\sigma_{A F}}{\sigma_{A F}+\sigma_{B F}}>1
\end{array}\right.
$$

i

$$
\begin{aligned}
& \sigma_{I F}=\frac{1}{M N-1} \sum_{m=1}^{M} \sum_{n=1}^{N}(I(m, n)-\bar{I}) \cdot(F(m, n)-\bar{F}) \\
& I \quad A, B
\end{aligned}
$$

Analizirani prozor ima težinu $\operatorname{sim}(\mathrm{A}, \mathrm{B}, \mathrm{F} / \mathrm{w})$ koja zavisi od sličnosti prozora izvornih i sjedinjene slike.

$\mathrm{Na}$ sl. 5 prikazane su dve izvorne slike, rezultati sjedinjavanja na dva načina i mape sličnosti blokova.

Ova slika pokazuje da sjedinjena slika $F_{1}$ sadrži više informacija izvornih slika nego slika $F_{2}$. Kada se posmatraju sličnosti blokova izvorne slike A i blokova sjedinjenih slika uočava se da je sličnost blokova veća u regionu izvorne slike koji je u fokusu (crni pikseli 0, beli pikseli 1). Takođe, uočava se da je veći broj sličnih blokova izvorne slike A i sjedinjene slike $F_{1}$ nego broj sličnih blokova izvorne slike $\mathrm{A}$ i sjedinjene slike $\mathrm{F}_{2}$. 


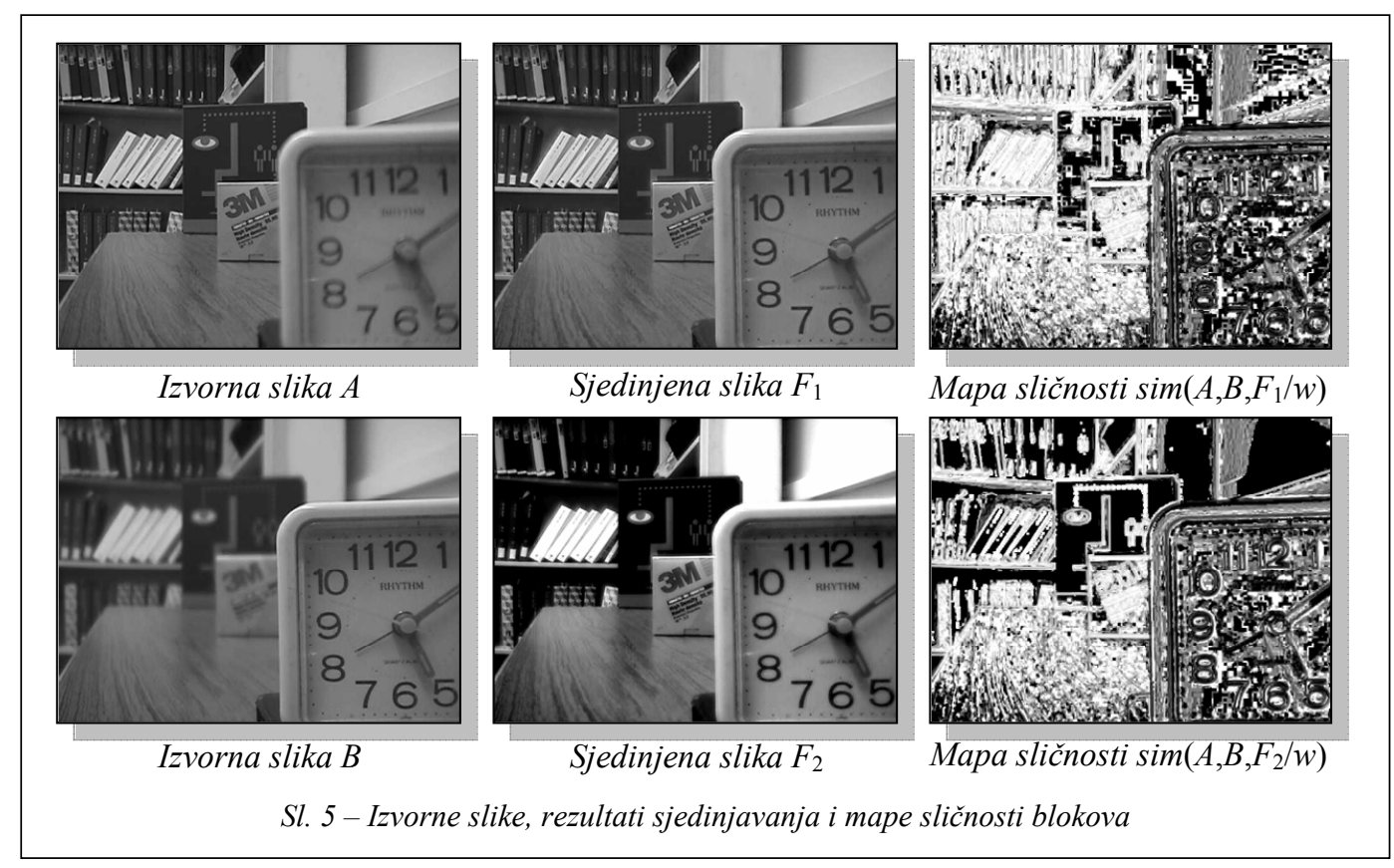

U tabeli 2 date su vrednosti mere $Q_{b}$ za izvorne i sjedinjene slike sa sl. 5 .

Tabela 2

Vrednosti mere $Q_{b}$ za izvorne i sjedinjene slike sa sl. 5

\begin{tabular}{|c|c|c|c|}
\hline Mera & $\begin{array}{c}\text { Dimenzije } \\
\text { bloka }\end{array}$ & $\begin{array}{c}\text { Sjedinjena } \\
\text { slika } F_{1}\end{array}$ & $\begin{array}{c}\text { Sjedinjena } \\
\text { slika } F_{2}\end{array}$ \\
\hline \multirow{4}{*}{$Q_{b}(A, B, F)$} & $4 \times 4$ piksela & 0,8060 & 0,5673 \\
\cline { 2 - 4 } & $8 \times 8$ piksela & 0,8362 & 0,6040 \\
\cline { 2 - 4 } & $\begin{array}{c}16 \times 16 \\
\text { piksela }\end{array}$ & 0,8627 & 0,6293 \\
\hline
\end{tabular}

Vrednosti predložene mere iz tabele slažu se sa subjektivnom procenom, tj. $Q_{b}\left(A, B, F_{1}\right)>Q_{b}\left(A, B, F_{2}\right)$, za sve tri dimenzije blokova. Takođe, može se primetiti da se sa promenom dimenzija blokova ne menjaju znatno vrednosti mere $Q_{b}$, što je u skladu sa zapažanjima u [6].

Da bi se optimizovale performanse sjedinjavanja, dalja istraživanja mogu se usmeriti ka izboru obeležja blokova (entropija, standardna devijacija, varijansa, ...). Umesto blokovske podele slika moguće je izvršiti segmentaciju izvornih slika i mere definisati za regione izvornih slika. Osobine vizuelnog sistema čoveka mogu se uključiti u objektivne procene na različite načine. Jedan od mehanizama funkcioniše kroz multirezolucionu analizu, jer prostorna rezolucija slike ima veliki uticaj na subjektivni kvalitet slike. U radu su razmatrane monohromatske slike a dalji rad može biti usmeren na primenu ovih mera u sjedinjavanju slika u boji.

\section{Poređenje objektivnih mera procene rezultata sjedinjavanja}

Poređenje objektivnih mera procene rezultata sjedinjavanja izvršeno je putem analize sjedinjenih slika dobijenih na različite načine. Analizirano je pet načina 
sjedinjavanja: sjedinjavanje DOLP piramida izvornih slika - DOLP [7], sjedinjavanje ROLP piramida izvornih slika ROLP [7], računarski efikasno sjedinjavanje - RES [8], aritmetičko sjedinjavanje - AS [8] i sjedinjavanje vejvlet transformacija izvornih slika - WAVE [9].

$\mathrm{Na}$ sl. 6 prikazane su dve izvorne slike dobijene niskofrekventnim filtriranjem komplementarnih delova slike „Goldhill““.

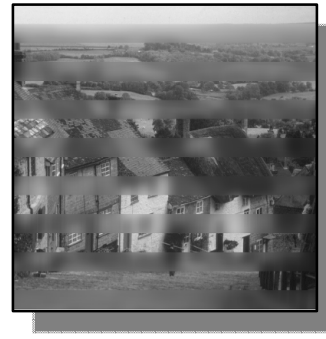

(a) Izvorna slika A

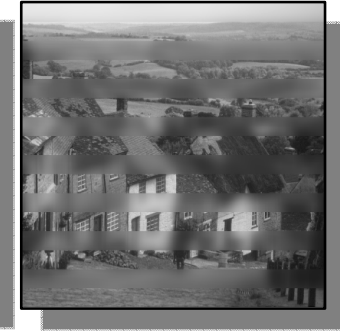

(b) Izvorna slika B

Sl. 6-Izvorne slike

Na sl. 7a prikazana je slika od koje su nastale izvorne slike prikazane na sl. 6. Na sl. 7b do 7d prikazane su sjedinjene slike.

Originalnoj slici „Goldhill“ vizuelno je najsličnija slika dobijena sjedinjavanjem DOLP piramida izvornih slika. Na drugom mestu po sličnosti originalnoj slici bila bi slika dobijena sjedinjavanjem vejvlet transformacija izvornih slika (procena autora).

U tabeli 3 prikazane su vrednosti opisanih mera objektivne procene rezultata sjedinjavanja izvornih slika prikazanih na sl. 6. Metode koje po analiziranim merama daju najbolje i najlošije rezultate sjedinjavanja obeležene su u tabeli crnom i sivom bojom, respektivno.

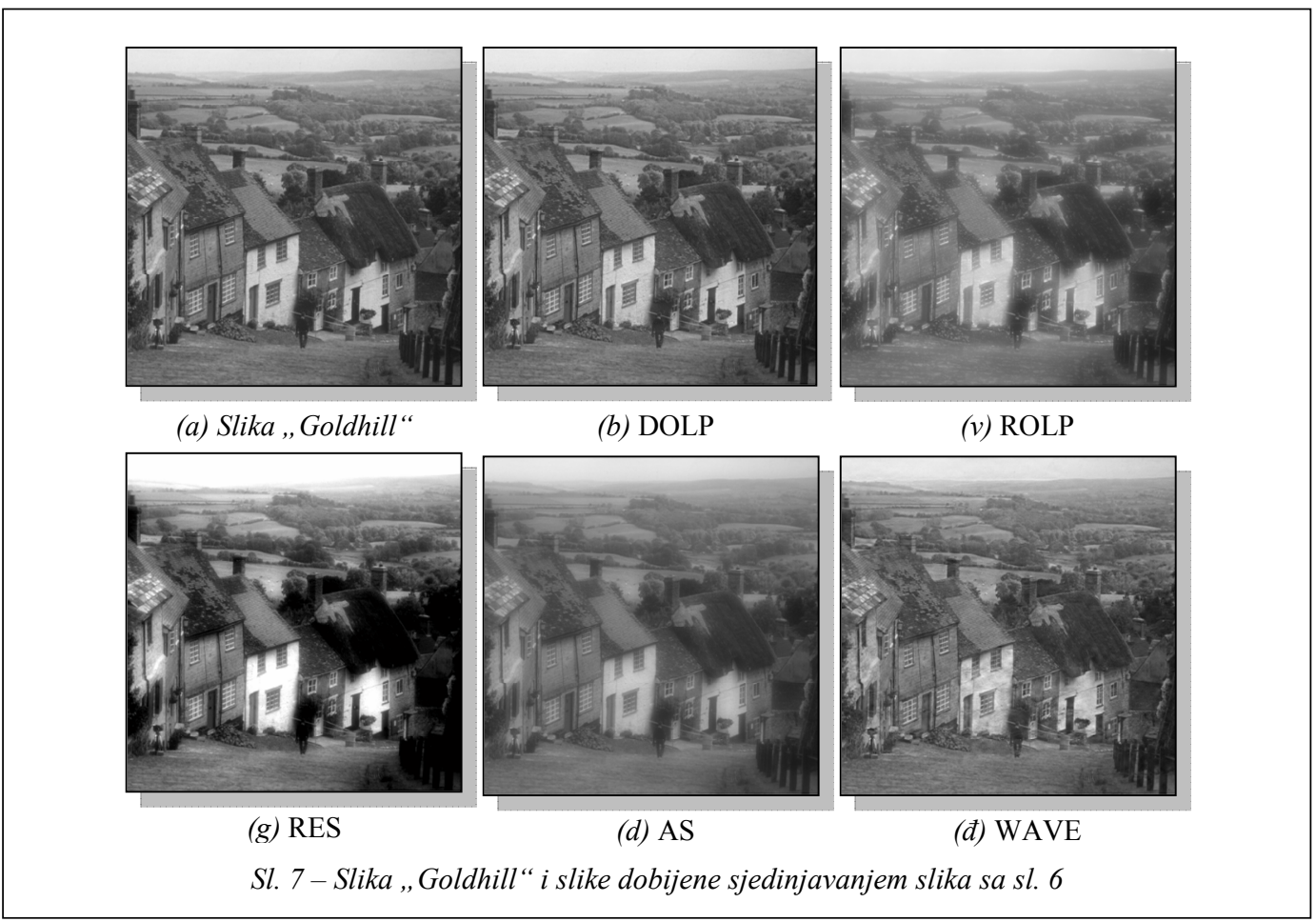




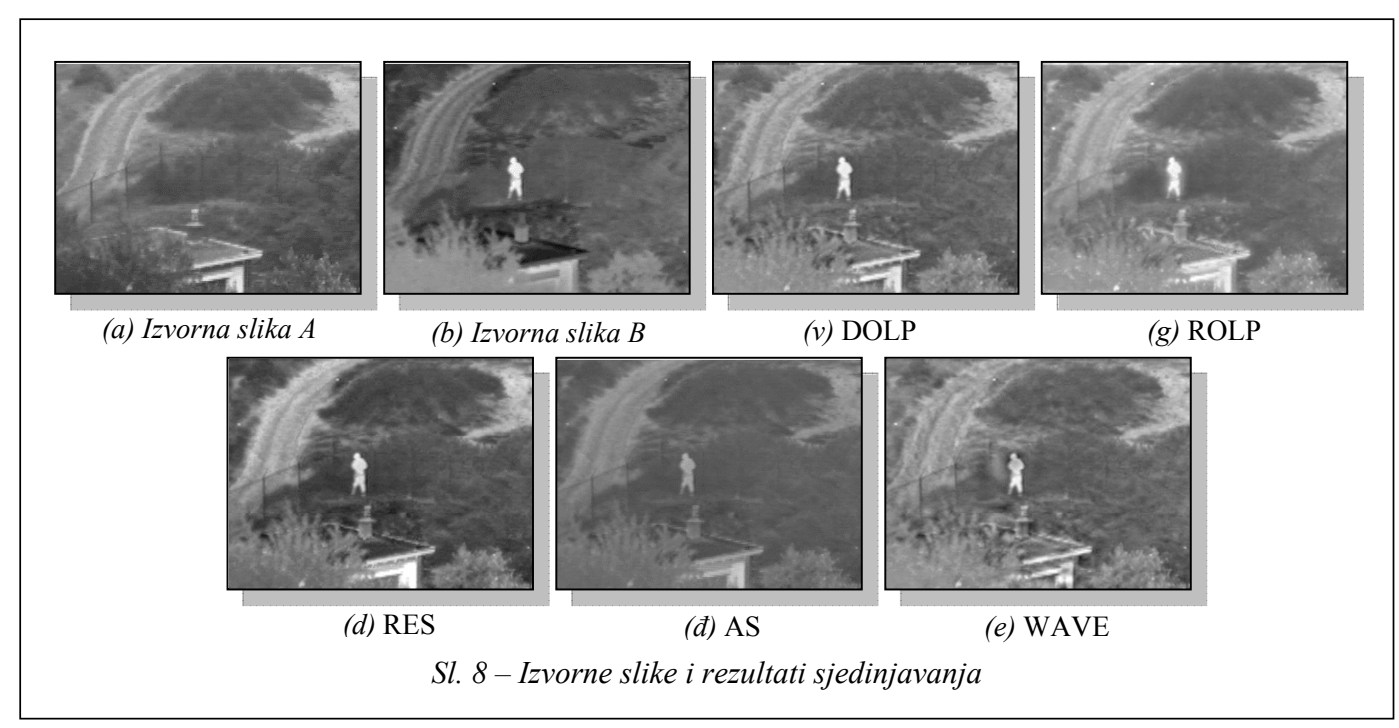

Tabela 3

Vrednosti objektivnih mera procene rezultata sjedinjavanja

\begin{tabular}{|c|c|c|c|c|c|}
\hline & DOLP & ROLP & RES & AS & WAVE \\
\hline $\mathrm{MSE}^{\mathrm{AB}}$ & $\mathbf{0 , 0 0 0 3}$ & 0,0041 & $\mathbf{0 , 0 1 3 9}$ & 0,0015 & 0,0009 \\
\hline $\mathrm{Q}^{\mathrm{AB}}{ }^{\mathrm{F}}$ & $\mathbf{0 , 7 8 8 3}$ & 0,4083 & 0,6917 & $\mathbf{0 , 3 3 4 9}$ & 0,6760 \\
\hline $\mathrm{MI}_{\mathrm{F}}{ }^{\mathrm{AB}}$ & $\mathbf{0 , 3 4 9 5}$ & 0,3421 & 0,2827 & 0,3173 & $\mathbf{0 , 2 8 0 6}$ \\
\hline $\mathrm{Q}_{\mathbf{b}}$ & $\mathbf{0 , 8 7 6 8}$ & 0,7300 & $\mathbf{0 , 6 9 0 4}$ & 0,7713 & 0,8218 \\
\hline $\mathrm{Q}_{\mathrm{w}}$ & $\mathbf{0 , 9 2 1 9}$ & $\mathbf{0 , 7 7 2 9}$ & 0,8400 & 0,7912 & 0,8898 \\
\hline $\mathrm{Q}_{\mathrm{e}}$ & $\mathbf{0 , 8 5 6 6}$ & 0,6557 & 0,7856 & $\mathbf{0 , 6 5 4 9}$ & 0,8123 \\
\hline $\mathrm{Q}_{\mathrm{b}}(4 \times 4)$ & $\mathbf{0 , 9 1 8 0}$ & 0,7148 & $\mathbf{0 , 6 9 1 7}$ & 0,7606 & 0,8549 \\
\hline $\mathrm{Q}_{\mathrm{b}}(8 \times 8)$ & $\mathbf{0 , 8 8 5 7}$ & 0,7295 & $\mathbf{0 , 6 7 4 6}$ & 0,7633 & 0,8357 \\
\hline $\mathrm{Q}_{\mathrm{b}}(16 \times 16)$ & $\mathbf{0 , 8 5 3 9}$ & 0,7574 & $\mathbf{0 , 6 6 2 9}$ & 0,7910 & 0,8180 \\
\hline
\end{tabular}

Po objektivnim procenama najbolji rezultati sjedinjavanja dobijeni su sjedinjavanjem DOLP piramida izvornih slika, što je u skladu sa subjektivnom procenom.

Analiza rezultata sjedinjavanja i objektivnih mera procene rezultata sprovedena je za televizijske i termovizijske slike sekvenci UNCAMP. Analizirano je 65 frejmova.

Na sl. 8 prikazane su dve izvorne slike televizijskih i termovizijskih sekvenci UNCAMP i rezultati sjedinjavanja po pet metoda.
Sjedinjene slike sadrže informacije obe izvorne slike. Veoma je teško izdvojiti metodu koja daje najbolje rezultate sjedinjavanja. Po proceni autora rada sjedinjavanjem DOLP piramida izvornih slika, računarski efikasnim sjedinjavanjem i sjedinjavanjem vejvlet transformacija izvornih slika dobijeni su bolji rezultati sjedinjavanja nego sjedinjavanjem ROLP piramida izvornih slika i aritmetičkim sjedinjavanjem.

Na sl. 9 prikazane su vrednosti analiziranih objektivnih mera procene rezultata sjedinjavanja, za svih pet metoda.

Sa sl. 9 vidi se da od 36. frejma počinju da rastu vrednosti analiziranih mera. Porast vrednosti nastao je zbog smanjenja amplitudske rezolucije izvornih slika. Vrednosti analiziranih mera imaju lokalne maksimume. Dodatnom analizom izvornih sekvenci ustanovljeno je da postoje podrhtavanja televizijske kamere u toku snimanja, što je uslovilo pojavu lokalnih maksimuma. Promena amplitudske rezolucije (osim kod mere MI) nije uslovila znatnu promenu redosleda metoda po kvalitetu sjedinjavanja. 


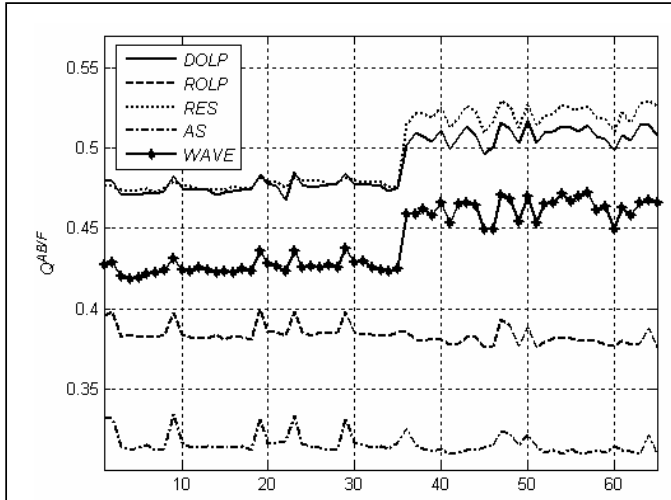

(a) $Q^{A B F}$

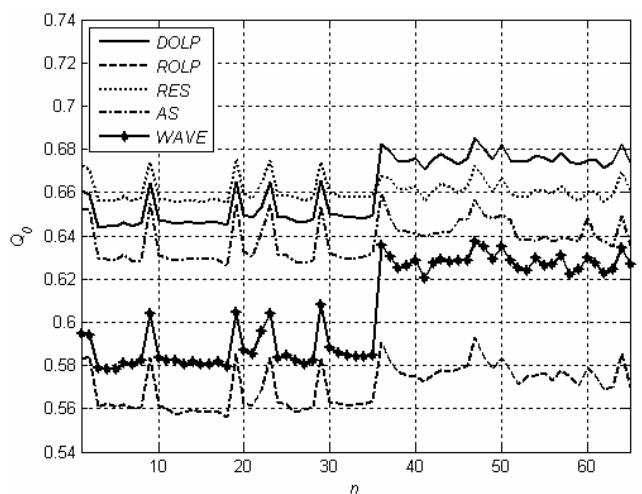

(v) $Q_{0}$

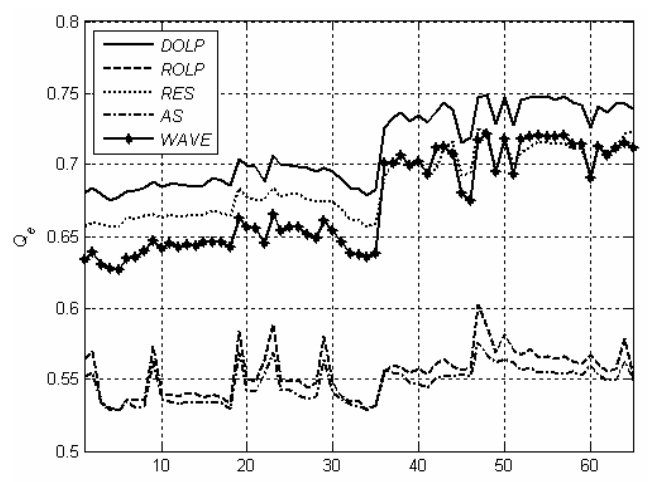

(d) $\stackrel{n}{Q}_{e}$

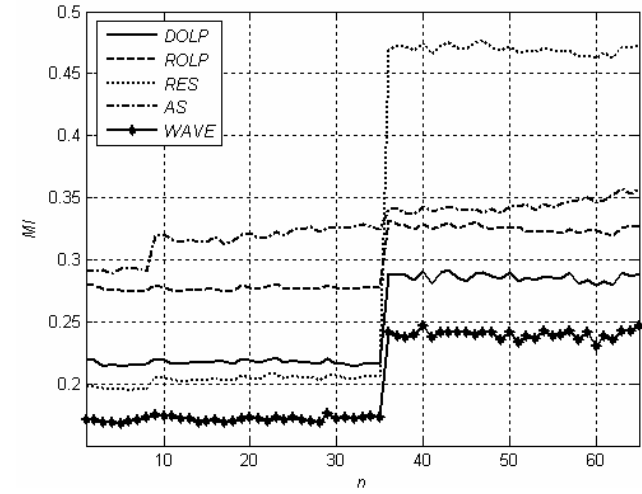

(b) $M I$

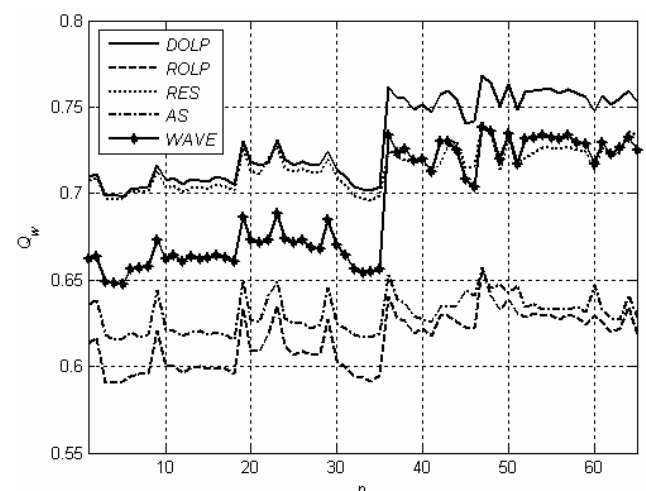

(g) $Q_{w}$

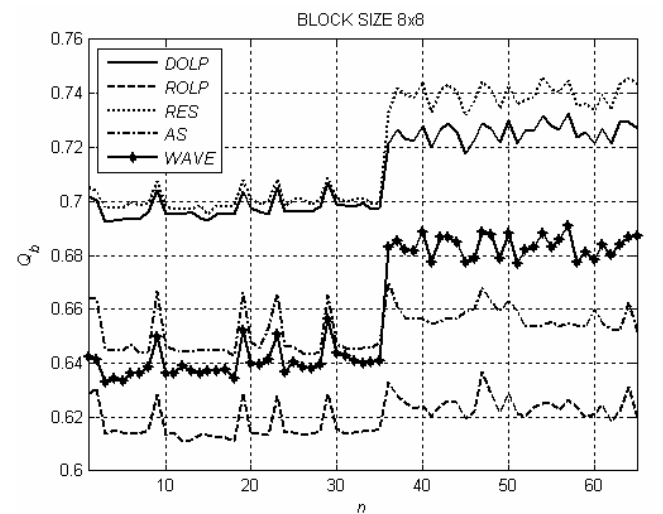

(d) $Q_{b}$

Sl. 9 - Vrednosti objektivnih mera procene rezultata sjedinjavanja

U tabeli 4 prikazane su srednje vrednosti objektivnih mera procene rezultata sjedinjavanja za 65 analiziranih frejmova i za svih pet metoda sjedinja- vanja. Metodi koji po analiziranim merama daju najbolje i najlošije rezultate obeleženi su crnom i sivom bojom, respektivno. 
Tabela 4

Srednje vrednosti objektivnih mera procene rezultata sjedinjavanja

\begin{tabular}{|c|c|c|c|c|c|}
\hline & DOLP & ROLP & RES & AS & WAVE \\
\hline $\mathrm{Q}^{\mathrm{AB} / \mathrm{F}}$ & 0,4908 & 0,3837 & $\mathbf{0 , 4 9 7 4}$ & $\mathbf{0 , 3 1 5 9}$ & 0,4429 \\
\hline $\mathrm{MI}_{\mathrm{F}}{ }^{\mathrm{AB}}$ & 0,2488 & 0,2992 & 0,3259 & $\mathbf{0 , 3 2 8 0}$ & $\mathbf{0 , 2 0 3 0}$ \\
\hline $\mathrm{Q}_{0}$ & $\mathbf{0 , 6 6 2 0}$ & $\mathbf{0 , 5 7 0 6}$ & 0,6610 & 0,6382 & 0,6056 \\
\hline $\mathrm{Q}_{\mathrm{w}}$ & $\mathbf{0 , 7 3 1 2}$ & $\mathbf{0 , 6 1 5 5}$ & 0,7146 & 0,6306 & 0,6932 \\
\hline $\mathrm{Q}_{\mathrm{e}}$ & $\mathbf{0 , 7 1 1 4}$ & 0,5549 & 0,6863 & $\mathbf{0 , 5 4 7 1}$ & 0,6740 \\
\hline $\mathrm{Q}_{\mathrm{b}}(4 \times 4)$ & 0,7263 & $\mathbf{0 , 6 3 8 4}$ & $\mathbf{0 , 7 2 8 7}$ & 0,6690 & 0,6840 \\
\hline $\mathrm{Q}_{\mathrm{b}}(8 \times 8)$ & 0,7102 & $\mathbf{0 , 6 2 0 1}$ & $\mathbf{0 , 7 1 8 4}$ & 0,6528 & 0,6601 \\
\hline $\mathrm{Q}_{\mathrm{b}}(16 \times 16)$ & 0,7103 & $\mathbf{0 , 6 2 6 5}$ & $\mathbf{0 , 7 2 9 9}$ & 0,6430 & 0,6540 \\
\hline
\end{tabular}

Za objektivne mere procene $\mathrm{Q}^{\mathrm{AB} / \mathrm{F}} \mathrm{i}$ $\mathrm{Q}_{\mathrm{b}}$ najbolji rezultati sjedinjavanja dobijeni su računarski efikasnim sjedinjavanjem, a za mere $\mathrm{Q}_{0}, \mathrm{Q}_{\mathrm{w}}$ i $\mathrm{Q}_{\mathrm{e}}$ najbolji rezultati sjedinjavanja dobijeni su sjedinjavanjem DOLP piramida izvornih slika. Ako se uporede vrednosti ovih pet mera za računarski efikasno sjedinjavanje i sjedinjavanje DOLP piramida izvornih slika, može se zaključiti da su srednje vrednosti mera veoma bliske. Izuzetak od ovih mera je mera MI, po kojoj su najbolji rezultati sjedinjavanja do 35 . frejma dobijeni aritmetičkim sjedinjavanjem, a od 36. frejma računarski efikasnim sjedinjavanjem.

Detaljna analiza objektivnih mera procene morala bi da obuhvati subjektivnu procenu rezultata sjedinjavanja i poređenje sa rezultatima objektivne procene.

Slike i sekvence korišćene u radu preuzete su iz baza slika i sekvenci dostupnih u [10].

\section{Zaključak}

U radu su opisane objektivne mere procene rezultata multisenzorskog sjedinjavanja slika. Mogu se svrstati u dve grupe: objektivne mere procene ukoliko je poznata idealna sjedinjena slika i objektivne mere procene koje se koriste kada idealna sjedinjena slika nije poznata. Idealna sjedinjena slika, osim u veoma specifičnim aplikacijama, ne može se dobiti, pa je u radu najveća pažnja posvećena merama koje ne koriste idealnu sjedinjenu sliku. Opisane su mere koje polaze sa tri različita stanovišta: transfera ivica od izvornih u sjedinjenu sliku, zajedničkih izvornih informacija i sjedinjene slike i distorzije blokova izvornih slika. Neke od opisanih mera uzimaju u obzir vizuelni sistem čoveka.

Analizom sjedinjenih slika, dobijenih na pet različitih načina, izvršeno je poređenje opisanih mera. Utvrđeno je da mera MI, zasnovana na zajedničkim informacijama, nekada daje rezultate koji nisu u skladu sa subjektivnom procenom.

Kako bi se optimizovale performanse sjedinjavanja, u radu su predloženi mogući pravci daljih istraživanja. Predstoji sprovođenje detaljne analize koja će obuhvatiti subjektivne testove i poređenje rezultata subjektivne i objektivne procene.

Zahvalnica: Istraživanja u ovom ra$\mathrm{du}$ su delimično finansirana od strane Ministarstva odbrane Republike Srbije.

Literatura:

[1] Popović, M.: Digitalna obrada slike, Akademska misao, Beograd, 2006

[2] Xydeas, C. S.; Petrović, V.: Objective Image Fusion Performance Measure, Electronics Letters, Volume 36, Issue 4, pp. 308-309, 17 Feb 2000.

[3] Qu, G.; Zhang, D.; Yan, P.: Information measure for performance of image fusion, Electronics Letters, Vol. 38, No. 7, March 2002.

[4] Wang, Z.; Bovik, A. C.: A Universal Image Quality Index, IEEE Signal Processing Letters, Vol. 9, No. 3, pp. 81-84, March 2002.

[5] Piella, G.: New quality measures for image fusion, Proceedings of the Seventh International Conference on Information Fusion, pp. 542-546, June 2004.

[6] Cvejic, N.; Loza, A.; Bull, D.; Canagarajah, N.: A Similarity Metric for Assesment of Image Fusion Algorithms, International Journal of Signal Processing, Vol. 2, No. 3, pp. 178-182, 2005.

[7] Toet, A.: Image fusion by a ratio of low-pass pyramid, Pattern Recognition Letters 9, pp. 245-253, 1989.

[8] Petrović, V.: Multisensor pixel-level Image Fusion, $\mathrm{PhD}$ Thesis, Manchester University, UK, 2001.

[9] Li, H.; Manjunath, B. S.; Mitra, S. K.: Multisensor Image Fusion Using the Wavelet Transform, Graphical Models and Image Processing Vol. 57, No. 3, 235-245, 1995.

[10] The Online Resource for Research in Image Fusion, http://www.imagefusion.org, 06. 07. 2007. 
